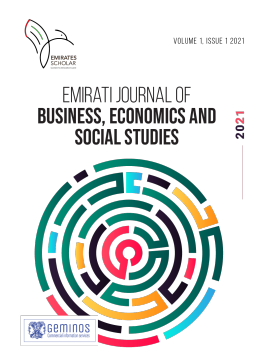

Emirati Journal of Business, Economics, and Social Studies

Vol 1 Issue 1 P: 4 - 302022

DOI: 10.54878

Emirates Scholar

Available at www.emiratesscholar.com

\title{
Standards of Building e-Learning Systems in Higher Education
}

Firas Habbal. PhD

Geminos Group

Research \& Development Department

Dr.firas@geminos.ae

\begin{abstract}
At the beginning of the $21^{\text {st }}$ century, virtual education has been positioned as an alternative modality, among other aspects, due to psycho-pedagogical advances and constant technological innovation. There has also been an exponential increase in educational proposals online due to the influence exerted by globalization and the increase in the use of information and communication technologies to provide educational services. Thus, virtual teaching and the development of learning objects represent permanent research phenomena in all disciplinary areas. Digital learning is characterized by the convergence of methods, technologies, applications and services aimed at sustaining learning via the web-portals. Therefore, online training considers as fundamental aspects for the learning development of skills in the management of technological platforms. It is also clear that online education is intended to penetrate the education market at all levels, and this is what also prompts reflection on the potential impact on education in the present century.
\end{abstract}

Keywords:

Standards, SCORM, E-Learning, Education, Self-Learning, Higher Education, Online Learning, Learning Models 


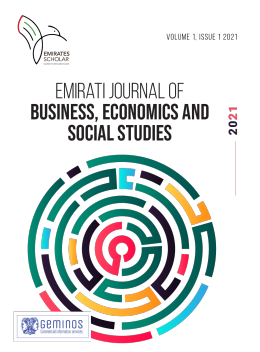

Emirati Journal of Business, Economics, and Social Studies

Vol 1 Issue 1 P: 4 - 302022

DOI: 10.54878

Emirates Scholar

Available at www.emiratesscholar.com

\section{Introduction}

The new technologies provided some tools and methods that play a great role in the improvement of learning approach, and the learning process in the recent years. In addition, it gives the opportunities to improve the learning implementation, which provided the effective learning environment that help in the activation of the learning process in a good manner. Because of the continuity of the technology revolution, which presents a quantum leap and a challenge for all the previous innovations and tools. Therefore, it was an obligation for all the researchers of this field to examine and research, to define the lied educational capabilities in the computers' capabilities. Thus, it is a great field to study, to examine the standards and criteria to ensure the educational outcomes, of the e-learning and educational programs.

As technology and web design have evolved, researchers have created and compiled rules and heuristics to enhance web design usability's attributes, such as navigation, accessibility, efficiency, and design. According to Sandoval (2016), these rules "give the direction to the designer to produce usable systems" (p. 88). Usability rules have been also applied in e-learning to evaluate online courses' usability. Researchers using heuristics have conducted several usability evaluations of e-learning settings. These evaluations focused on the web design aspects of the courses. However, since the purpose of e-learning is not only to provide an interface for an online learning environment, but also to support the acquisition of knowledge through it, the traditional usability instruments are not sufficient.

\section{Literature Review E-learning Definitions}

There are many modern concepts that did not get the accurate and agreed definition, and e- learning is one of these new concepts. Such as computer based learning, technology-based training, and computer-based training. In fact, some authors consider e-learning to be a new generation of distance education, even as they point to significant differences between the two and highlight a key starting point: "E-learning does not represent more of the same as It is about doing 


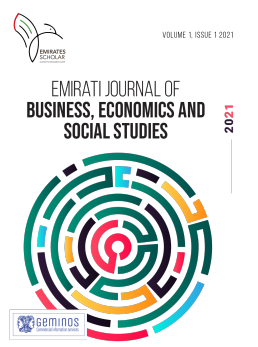

Emirati Journal of Business, Economics, and Social Studies

Vol 1 Issue 1 P: 4 - 302022

DOI: 10.54878

Emirates Scholar

Available at www.emiratesscholar.com

things differently" (Garrison \& Anderson, 2003). Thus, Guri-Rosenblit (2005) has defined the word (Electronic), by "E-learning is the use of electronic media for a variety of learning purposes that range from add-on functions in conventional classrooms to full substitution for the face-to face meetings by online encounters". Therefore, there are many definitions for e-learning, as: "Elearning is to take a course online using a modem, wireless, or cable connection to access academic course material from a computer, phone, or handheld device" (Governors State University, 2008). Further, "E-learning is distance education through remote resources" (Marquès, 2006). According to E-learning Portal (2009) "E-learning is the use of technology to deliver learning and training programs" (p.10).

Therefore, e-learning is "An educational system, which uses information technology and computer networks in supporting and expanding the scope of the educational process, through some methods; as computers, internet and software that was prepared by specialists or companies" (Marquès, 2006). Considering that usability was first applied to software development, Sandoval (2016) argued that it could be measured from different views: the product-oriented view, the useroriented view, and the user-performance view. Most usability guidelines recommended in the literature are user-performance oriented, which include evaluating the ease of use and acceptability of the software or webpage by the user. According to Rennie and Morrison (2013), these guidelines "give the direction to the designer to produce usable systems" (p. 60), so that course designers and instructors have a guide for developing online courses.

In addition, Naber \& Kohle (2006) defined e-learning from the scope of internet, the network that enriched the life of all persons, in all fields and facilitated the communication and education process. In the same time, this network is very complicated because of its composition, cluster network, programs and its programming. The technology-based education was a simple process, as it can be divided into the "time scale" and the "place scale". The "time scale" is divided to "synchronous" as seminars, TV programs and others. The second is "Asynchronous" as audio and video tapes, whereas the place scale is divided to Tele-media, on a time scale as TV and audio 


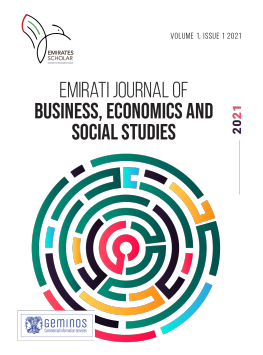

Emirati Journal of Business, Economics, and Social Studies

Vol 1 Issue 1 P: 4 - 302022

DOI: 10.54878

Emirates Scholar

Available at www.emiratesscholar.com

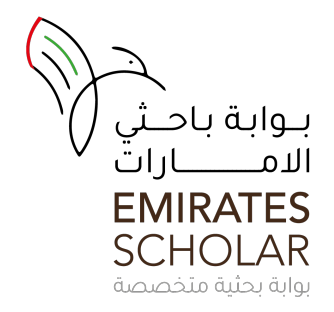

programs, and Local Media. The researcher's views are that the based technology educational media can be divided to synchronous media, like TV broadcasting and asynchronous like video tapes, as it can be reviewed in any time. Naber \& Kohle added that internet has changed all that by "integration", whereas education happens in all times, and the learner can save it be restored in any time. It could be broadcasted for one person or more in the suitable time.

Hassan (2015) argued that there are three principal usability evaluation procedures:

(1) Expert review,

(2) Simulation trials, and

(3) User performance tests.

Based on this, usability guidelines can be used in different ways. For example, they can be used as a checklist for designers that includes all the basic elements to create a usable product or as a checklist where usability experts can evaluate a product's usability. In addition, these guidelines can serve to measure a website's usability based on the users' performance and perception about the product.

\subsection{Types of E-Learning: Direct E-Learning}

It means the educational tools and methods that are based on technology, to deliver and exchange lessons and researches between the learner and the teacher. Thus, the concept of elearning includes many technologies and methods, whereas 80 s have witnessed the utilization of CDs for education, but it was having a disadvantage, which is the lack of interaction between the learner and the teacher. Then emerging of internet was the justification of its utilization in the direct e-learning, to simulate the real learning methods, as it gives the humanity aspects through the direct interactions among the stakeholders of the educational process, and we have to differentiate between technology education and education technology (Leidner \& Jarvenpaa, 1995).

\subsection{Computer Based Training (CBT)}




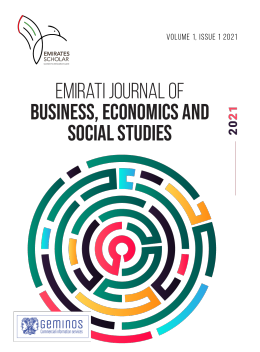

Emirati Journal of Business, Economics, and Social Studies

Vol 1 Issue 1 P: 4 - 302022

DOI: 10.54878

Emirates Scholar

Available at www.emiratesscholar.com

Computer Based Training is still the synonymous of the traditional education and it can be used as some supplementary methods within a comprehensive training and education plan. As, it depends on some methods and technologies; for example, if it was hard to broadcast the educational video through internet, so it can be presented on $\mathrm{CDs}$, as long as it contributes in improving the quality and level of training and education, and prevent the overcrowding on the network (Rahmana, Kamil, Soemantri \& Olim, 2014). Moreover, e-learning needs a strong justification for its utilization and investment in it, which will be the insights of using it on the long run, in order to prevent any obstacles and challenges of IT. E-learning can be divided, according to time scale, to (synchronous) and (asynchronous), and according to e-learning methods by the needed requirements. In this respect, self-assessment refers to the opportunities that e-learning students have to evaluate their own learning as they progress through the course. Through self-assessment, students are able to identify their progress, as a well as strengths and challenges they experience in their own learning. Learnability refers to the ease with which users can remember how to navigate a web page after they have visited it. In addition, learnability posits that once the user navigates a web page for the first time, it should be easier to remember where to find something the next time.

\subsubsection{Impact of E-Learning on the Learning Process}

Internet utilization - as a main tool for e-learning- can put both of learners and teachers in front of the main fact that internet can provided them with the required information through one click. This will protect them from the effort of saving and studying the whole subject. Why they do all that efforts in this time, when the internet can provide all the needed information in any time? Do students now have the opportunity to focus on the quality of logic thinking and analysis, more than focusing on quantities and saving? According to these, the main changes in the field of Education could be summarized as follow aspects include all the education institutions will be closely related with the required technologies, with the amount that enabling it to keep up with 


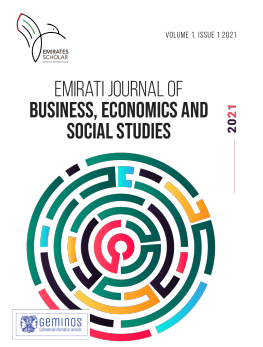

Emirati Journal of Business, Economics, and Social Studies

Vol 1 Issue 1 P: 4 - 302022

DOI: 10.54878

Emirates Scholar

Available at www.emiratesscholar.com

modern technologies. Further, teachers can improve their educational skills to keep up with the IT and modern technologies (Rennie \& Morrison, 2013), with the amount that enable them to continue their progress in the educational field. The required computers and technologies will provide students in an early period of their educational period. Moreover, the focus in the classes will be on analysis, logical thinking and knowledge improvement more than saving hardship. Therefore, teachers will be to help their students to understand the hard concepts, gain more educational attainment, and to meet the students' necessary requirements in a better manner, because e-learning can work on enhancing the educational process and improve the students' educational attainment.

As there will no need to select a specific book, whereas there is a wide range of available books through the direct and indirect communication. As, internet provides a great amount of information that limit the option of choosing only one book. Further, all books and periodicals are scanned to be saved electronically on the internet, because the electronic saved books can be accessed and restored easily, other than the paper books that can be damaged over time, and it can be useless. This will reduce the education costs; because there will be no need for huge library buildings, and reduce the loss that can be damaged easily. All what will be needed is the cost of technology hardware and software. Further education will overcome time and place constrains, and get rid of seminars and constrains that limit the education process inside the halls. For now, we can create video conferences, save many things because of modern technology, and explore the concept of logical analysis and thinking. Therefore, the education process will be a service and benefit available for all.

\subsubsection{Advantages of E-Learning}

It is clear now that the increase of the tendency toward E-learning is because of its great benefits. As, we in the E-faculty of Comprehensive Quality, see great education and training opportunities in E-learning. Whereas, E-learning can benefit you and also can benefit the 


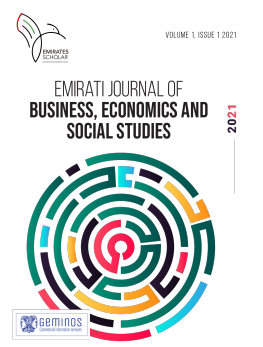

Emirati Journal of Business, Economics, and Social Studies

Vol 1 Issue 1 P: 4 - 302022

DOI: 10.54878

Emirates Scholar

Available at www.emiratesscholar.com

educational institution, but some cannot gain these benefits, so we need to decide clearly, where those benefits are and how to get benefit from them. As, this is a kind of education witnesses an increasing demand from all the community segments, to be a supplement method for the traditional education. However, this kind of learning is characterized with its flexibility, economic efficiency, and getting rid of all time and place constrains, which enhanced the increasing demand of ELearning from the whole society. The main factors that increase adoption of E-learning technology in higher education (Fresen, 2011). According to Fresen (2011), this can be due to variety of reasons such as inadequate infrastructure for access, support and training for sustaining technology. Lack of coordinated planning for technology at departmental, institutional and system levels. Since, use of technology is not part of the prestige, recognition or promotion systems currently in place. Further, academic staff have not been taught how to apply technology to teaching. Regarding this, technology is not a financial priority within schools or departments. uncertainty of intellectual property rights in an electronic environment results in the resistance to changing traditional teaching practices that further results in the lack of understanding of application of technology, lack of high level vision in administration about the role of technology, unrealistic expectations of what the technology can do and dismissive attitude because of early inadequate experience (real or perceived). Further generational division between older and younger staff in responding to use of technology yield resistance to external pressure to change, ideological resistance to technology and claims that technological solutions are pedagogically not appropriate.

The advantages of e-learning are demonstrated by Cohen (1992) in the following aspects that include time flexibility, as the learner can choose the suitable time for him, without engaging with fixed time. Further, provide the learner with the suitable place for him. The possibility of getting benefits from many important factors as [sound - text - color - video - font type presentation methods and others], therefore, the learner can use all his senses in the learning process. It does not depend on the learner's age, as it is suitable for adults, employees or children, 


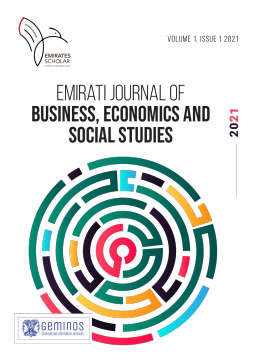

Emirati Journal of Business, Economics, and Social Studies

Vol 1 Issue 1 P: 4 - 302022

DOI: 10.54878

Emirates Scholar

Available at www.emiratesscholar.com

who cannot go and attend schools and universities in certain times. Moreover, many educators, who prefer e-learning, see that e-learning is cost effectively. It provides the teacher with more information, as long as he has the ability to gain more. Thus, we can conclude some advantages of e-learning from some education references, as (Arkorful \& Abaidoo, 2015) reported that it is flexible when issues of time and place are taken into consideration. Every student has the luxury of choosing the place and time that suits him/her. According to Smedley (2010), the adoption of e-learning provides the institutions as well as their students or learners the much flexibility of time and place of delivery or receipt of according to learning information.

Further, e-learning enhances the efficacy of knowledge and qualifications via ease of access to a huge amount of information. It is able to provide opportunities for relations between learners by the use of discussion forums. Through this, e-learning helps eliminate barriers that have the potential of hindering participation including the fear of talking to other learners. Elearning motivates students to interact with other, as well as exchange and respect different point of views. E-Learning eases communication and improves the relationships that sustain learning. Wagner, Hassanein and Head (2008) noted that e-Learning makes available extra prospects for interactivity between students and teachers during content delivery. E-learning is cost effective in the sense that there is no need for the students or learners to travel. It is also cost effective in the sense that it offers opportunities for learning for maximum number of learners with no need for many buildings. Therefore, e-learning always takes into consideration the individual learners differences. Some learners, for instance prefer to concentrate on certain parts of the course, while others are prepared to review the entire course. E-learning helps compensate for scarcities of academic staff, including instructors or teachers as well as facilitators, lab technicians etc. The use of e-Learning allows self-pacing. For instance, the asynchronous way permits each student to study at his or her own pace and speed whether slow or quick. It therefore increases satisfaction and decreases stress (Codone, 2001; Amer, 2007; Urdan \& Weggen, 2000; Algahtani, 2011; Marc, 2002; Klein and Ware, 2003). 


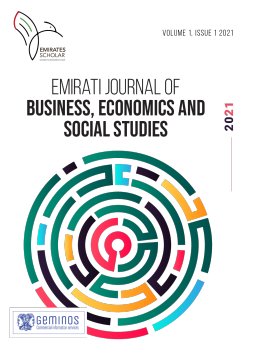

Emirati Journal of Business, Economics, and Social Studies

Vol 1 Issue 1 P: 4 - 302022

DOI: 10.54878

Emirates Scholar

Available at www.emiratesscholar.com

\subsubsection{Literacy Standards Standard Specification of E-Learning}

In most of industrial countries, education is one of the most important social and economic activity. Therefore, it must get the suitable care from the aspects of costs and efficiency; especially that these two aspects are closely related to the modern media technologies, whereas, in the resent eras the education process depends widely on communication technology. Thus, the educational and training institutions invest huge amounts of money in e-learning, which are millions of dollars. As now, we cannot find any educational institution without electronic educational or electronic training program beside the traditional one. Whereas, the educational institutions have entered into many projects that use various strategies and models (Aldalalah \& Ababneh, 2015), but to reach effectively the planned objectives for each institution, it is important for each institution to seek for creating common factors for common interfaces to decrease costs and get broad benefits from the digital learning object. Therefore, to achieve this objective, it was necessary to search for a frame that enable the use and re-use of the learning objects.

Since, learning object (LO), from the side of all stakeholders, with some certain standards for all learning objects, which enable the exchanges among e-learning systems. In the light of what mentioned, this research will explore the concept of standard specification and all the players of this field, and the concept of standardization. Therefore, standard specification, to define the concept of e-learning and used standard specifications, we need to differentiate between two groups of elements; the first group contains the physical elements. The elements that has physical and electronic presence - as the files, facilitation programs and databases. The other group is the elements that are intellectually designed and produced as lessons and training briefcases, which are called Learning Object. The size and usage of these groups vary, but it remains be able to be used and beneficial in other applications, lessons and briefcases. Therefore, the creator of the learning object has to give care to define and index this object by the International Standards, to be used and defined from all Learning Management Systems (LMS), to create the interfaces of 


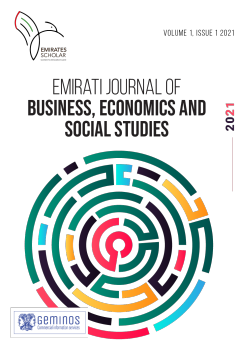

Emirati Journal of Business, Economics, and Social Studies

Vol 1 Issue 1 P: 4 - 302022

DOI: 10.54878

Emirates Scholar

Available at www.emiratesscholar.com

these learning objects by using the International Standards.

In fact, the standards of e-learning could provide the required flexibility for the educational structures. For example, the successful academic content for any system cannot be used in any other system, unless great modifications are applied. Whereas, if institution bought the license of certain software, it will find that this software can be used only in one system and it is related to a certain interface that has its methods and requirements, to reach its database and it may lose its efficiency. Therefore, it is now important to give care to the standard specifications of the elearning objects, to develop this kind of education, and to maximize its Return on Investments (ROI) (Zamfir, 2008). It was noted that the developing of the standard specifications was successful in (Internet), as we now use these specifications on daily basis, because we cannot use the internet without the specifications of TCP/IP, or HTTP, or HTML. Therefore, for the specifications of elearning, there is a widely spread usage for a technological measurement from extended Markup Language XML, which is now used in many applications as an option to exchange many interfaces. For example, this language gives the tools that create and protect the files structured in text format, which can be re-used in different way, as one of the most important objectives of the standard XML language, is to differentiate between the content format and the display format.

\subsection{Advantages of Standard Specifications}

There are four objectives to develop and use the standard specifications:

1. Accessibility: it helps in indexing and searching for classified objects apart from the used system.

2. Interoperability: it means the possibility to work with all types of systems, devices, browsers, and databases.

3. Durability: it means the exceeding of amendments requirements during the development of systems and programs.

4. Reusability: that enables amendments and usage by many development tools. 


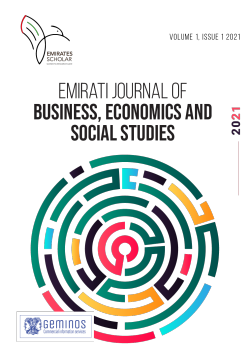

Emirati Journal of Business, Economics, and Social Studies

Vol 1 Issue 1 P: 4 - 302022

DOI: 10.54878

Emirates Scholar

Available at www.emiratesscholar.com

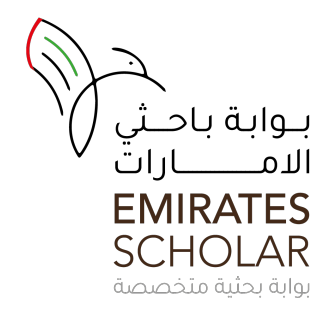

\subsubsection{The Developers of the Standard Specifications of E-Learning}

Here, the researcher can classify the workers in this field in three main groups. First, the developers, who develop the private applications that can be generalized later, and converted to standard specifications. Second, those who apply these specifications in the case of development and save it in a certain environment. Then, the last one is the institutions that ensure the validity and authentications of these specifications. Provided that, they are all working in a great coordination in every stage, to be able to generalize these standard specifications in e-learning.

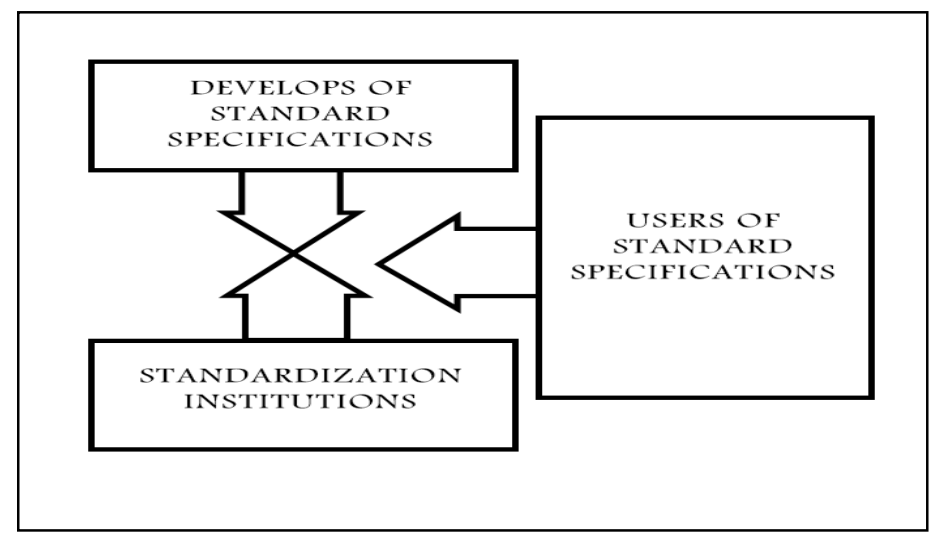

Fig. 1 Components of developing e-learning standard specifications.

From the main institutions that dominate the application of the standard specifications in the American institutions like Sharable Content Object Reference Model (SCORM) of Advanced distributed learning -American defense and academic teaching. Which integrated the qualitative properties of the educational subjects of some institutions like IMS Global Learning ConsortiumUnited State and Aviation Industry CBT Committee (AICC). 


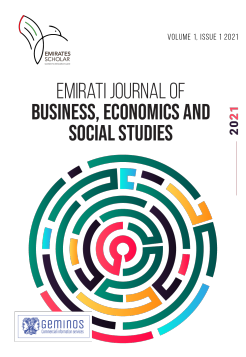

Emirati Journal of Business, Economics, and Social Studies

Vol 1 Issue 1 P: 4 - 302022

DOI: 10.54878

Emirates Scholar

Available at www.emiratesscholar.com

\subsubsection{SCORM International System}

It is an essential standard protocol for the communication between the single education subject and LMS, whereas this educational subject is called SCO, the abbreviation of SCORM (Bouras, Nani \& Tsiatsos, 2003). This single educational subject is the main unit of education, which is looking for a certain objective, and able to communicate with a certain facilitating system that define the learner's results, the period of study, and his progress in the educational attainment. To achieve these objectives, SCORM protocols recommends some rules that need to be followed during the design and development of the training materials, to be harmonized with this system and independent in the same time. Thus, there are many companies that developed the "Authorizing System", which enable the conversion of a certain file from Microsoft system to any suitable system for SCORM.

\subsubsection{Relationship between Database and Learning Management System}

The following figure clarifies that Learning Management System communicates with the Database to store and find the information, because the single educational subjects don't communicate directly with the database, as it asks the Learning management system first, through SCORM Protocol about the needed information (Deperlioglu, Sarpkaya \& Ergun, 2011). Therefore, we can conclude the following result as SCORM system is a communication language between the relation parties; that is Learning Management System and the Database. When, the training material is ready, it sends. The information to LMS through SCORM protocol, so LMS will save this information in the Database, if required. To understand the standardization cycle, we have to explain the main stages of the standardization process, or the approval of the standard 


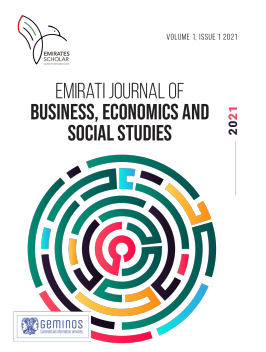

Emirati Journal of Business, Economics, and Social Studies

Vol 1 Issue 1 P: 4 - 302022

DOI: 10.54878

Emirates Scholar

Available at www.emiratesscholar.com

specification for e-learning project.

Fig. 2 SCORM System.

\subsubsection{Standardization Cycle}

Standardization cycle will pass through clear certain stages:

Primary stage: it is the process in which the developer defines the usage requirements of the learning object, through knowing the users' requirements. In addition, he will define the technologies to be used, whereas the developer in this stage has to develop the terms of reference, or the object's burdens, which need to be market. Second stage: it is the stage of defining the qualitative specification for the "learning object", whereas the technical message will be defined, to reach the planned qualitative specification of the object. This will be done through experiences and experiments before reaching the final objective.

Third stage: it is the process of calibration and evaluation of the qualitative specification in its final format, whereas the reference's models and the guidelines will be developed for the

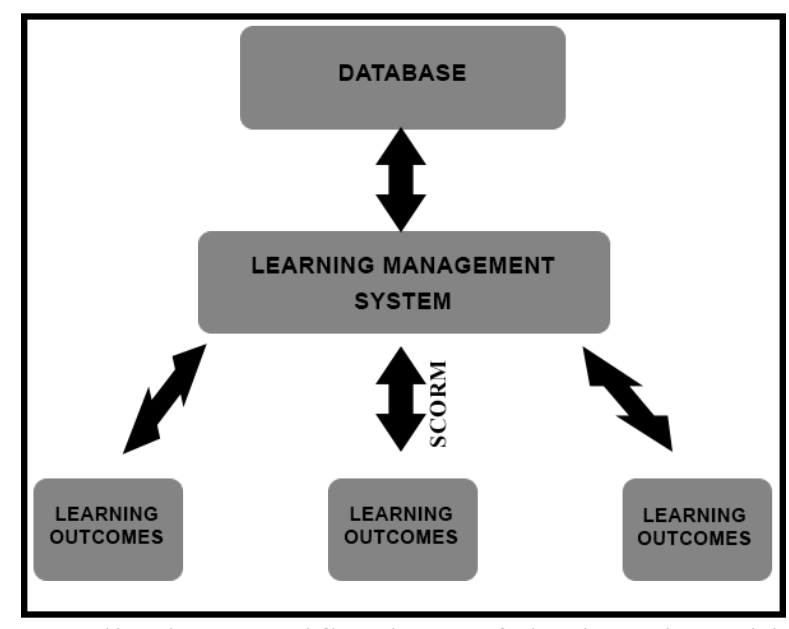

qualitative specifications of the learning object. Then, after many experiments, we will reach the stable specifications. Fourth stage: it is the standardization process, which depends on the final models of standardization and the final standard specifications, then present it to the internal and external standardization institutions. Fifth stage: it is the certification stage of the standard specifications for the learning object, in its final format and content. Thus, it will be approved as 


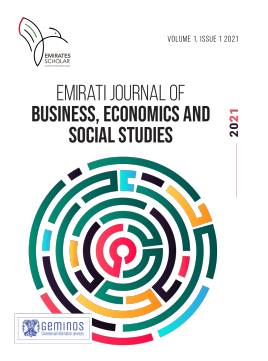

Emirati Journal of Business, Economics, and Social Studies

Vol 1 Issue 1 P: 4 - 302022

DOI: 10.54878

Emirates Scholar

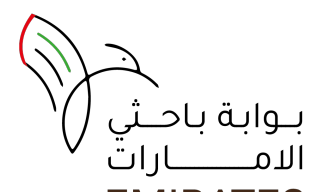

EMIRATES

SCHOLAR

Available at www.emiratesscholar.com

a standard learning object, which can be used in all the educational environments and able to interact with many interfaces. From the institutions that apply the standard specifications in elearning, according to the development happened in the American institution "IMS", we can mention the Canadian institution "CANCORE", or the American "SCORM", which gives us a distinctive example on how to create protocols in e-learning. Whereas, the later enables the researchers and the browsers to reach the educational information or object in easy manner. As, SCORM's protocol depends of many types of metadata, in order to define the learning objects. Such as general category, that enables the identification of the learning object, regardless of its environment. Further lifecycle category that uses four elements, to define the circumstances of creating the learning object, and it includes the name, creation date, and publication details. Another is metadata category that includes the file metadata, who contributed in its development, and who approved this file. In addition to the file's language, creation date, and certification date. Moreover, technical and educational category uses five elements to define the technical format of the learning object, its size, location, specification, importance and the user's language. An important are the right and relations categories, which includes three elements, which define the terms of use of the learning object, and its relation with the other educational methods. Finally, classification category that consists of four elements that accept all specifications regardless of its type and format.

Thus, standardization in e-learning becomes one of the main challenges in the coming years. Therefore, many international institutions have emerged to generalize their views, and their standardization technologies on all aspects. Therefore, it was essential for the institutions in the Arab World to keep up with those technologies, because it is clear for all the participants of this field that technologies become very important, and it is important to be used in media and communications, in order to improve the educational process. There are many designs that can be the basis of the vision of how the program works; how the learner will control it; the inputs, outputs and the selections among the available choices. For example, if the student is reading a book, he can get back to review a certain information, or go forward to reach a certain page. Therefore, the 


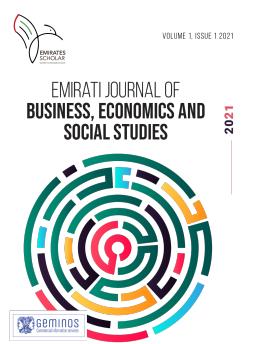

Emirati Journal of Business, Economics, and Social Studies

Vol 1 Issue 1 P: 4 - 302022

DOI: 10.54878

Emirates Scholar

Available at www.emiratesscholar.com

student can control the sequence of his lessons and activities, depending on his educational needs. Using the same method, the computer enables the student to go in everywhere using some options and designs, as:

\section{a) Linear Design}

It is one of the simplest methods for programs' design, as it obliged all users to follow the same educational steps in the program. If the student needs to understand a certain concept, he has to follow the procedures defined by the program, in the same order of information, examples and exercise. The main advantages of this type, is its full control of all the procedures of the educational process, also this types is less complex than other designs. Moreover, this design is beneficial and effective if the learners' levels are homogenous, and it is not suitable for uneven students, because there is no opportunity to skip some information for speedy learner, or to get back for slow students. Some refuse to use this kind of design because the lack of flexibility and it does not use Decision Making methods, which represent advanced capabilities for the program.

\section{b) Branching Design}

The computer's ability to individualize the educational process is considered the best service provided, whereas this ability appeared when computers evaluate the responses of each learner, and define his needs to progress in study/revision. In addition, the branching options in any programs are considered one of the main factors, which the program depends on to present an individual evaluation. Thus, branching means; the program's ability to go back or forward, or go to any specific point, according to the user's request. Moreover, the others use branching inside the program to skip some exercise, in order to reach the next exercise, or study a certain lesson without passing; therefore, we can find many types of this branching in computerized lessons:

\section{c) Forward Branching}

It means moving from a point to a forward point in the program, as it depends on the learner's request and the study requirements. There are two types of forward branching such as forward branching that depends on the learner's performance as it happens according to a certain condition defined by the program's designer, as it goes to a certain point when the answer is right 


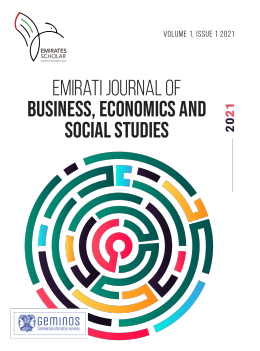
Emirati Journal of Business, Economics, and Social Studies
Vol 1 Issue 1 P: 4 - 302022
DOI: 10.54878
Emirates Scholar

Available at www.emiratesscholar.com

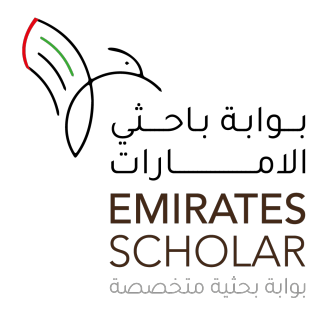

(Alonso, López, Manrique \& Viñes, 2005). On the other hand, forward branching that depends on the learner's preferences: it happens according to the learner's preferences, whether he needs to go forward, or he will skip the next exercise in the option's list.

\section{d) Backward Branching}

In many cases, it is important to transfer from a subject to another previous one, or what is called the reverse transformation process through the program information, in order to reach the program's start by backward branching. This kind of branching is very important in the need of reviewing a certain point of the program. This happens when the learner fails in responding to the program's requirement, so he will get back to the subject, to revise and study it again.

\section{e) Random Branching}

It is a special case of branching, and it is used when the sequence of the program is not important. It allows both mentioned kinds of branching without depending on any logic sequences of the subject. From the previous explanations for the different designs of computers; we can conclude that there are two main types of program designs according to the branching option, first (Linear), which is a main part of creating the program, and it happened in all conditions, regardless of the learner's preferences. The second is (Branching), which is conditioned by special terms according to the desires of the program designer, whereas this type is characterized by its ability to face the individual differences, and it also permits the creation of a program with many options according to the learner's needs.

\subsubsection{Development of educational software}

Educational software is considered one of the modern methods that need time, effort and money to create it, as it differs totally from the traditional media. These modern methods have two ways; it requires an interaction from the learners, while most of other media are considered on way methods. Therefore, to reach the targeted level of the educational software, which will be able to simulate the human model, the following aspects have to be taken into account in the development 


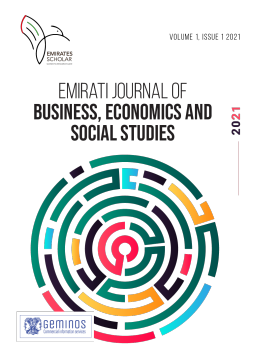

Emirati Journal of Business, Economics, and Social Studies

Vol 1 Issue 1 P: 4 - 302022

DOI: 10.54878

Emirates Scholar

Available at www.emiratesscholar.com

of any software:

\section{1- Display Style}

It means the followed strategy to display the educational subject for the learner, whether it was texts, diagrams or both of them. Whereas, computers are not only advanced audio-video tool, but also it has dynamic nature that can provide many display styles, for presenting and processing the texts. The question hers is; what is the basis theory of good text production? What are the main points that we need to consider, in order attracting the learner to certain points? In addition, how to avoid the problems related to the computers as screen size, the screed degree of display accuracy as compared to books? Therefore, in general the following will present some recommendations for good display (Hassan, 2015).

\section{2- Display Main Considerations}

Let the format of display screen defines the program creation method such as Display style has to focus on the program structure, because the followed display style is the main determinant the used strategy of linking the program scientific content and it is linking style on the display screen. Therefore, the designer has to take into account that the display screen is not just a secondary interface to present information, but it is a linking point that will change the navigation procedures through the program. Therefore, simple design is one of the main required of successful display style.

\section{3- Texts Presentation}

Texts play an important role in delivering information for the learner, as it presents information, explain the diagrams, and provide the learner with important instructions that determine the program success. Moreover, the positive role of texts in the programs is very different from in books. As in programs, the learner will be able to branch forward and backward. In addition, the paragraph style of books is not suitable for digital screens, so it has to be replaced by brief texts, separated by short space, to facilitate the learner's process in reading these texts. Therefore, texts have to be rewritten in short bulleted phrases, to facilitate the navigation process.

All the screen components have to be clear, but in the same time, it is preferred to highlight 


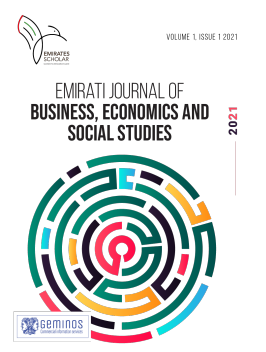

Emirati Journal of Business, Economics, and Social Studies

Vol 1 Issue 1 P: 4 - 302022

DOI: 10.54878

Emirates Scholar

Available at www.emiratesscholar.com

a certain paragraph because of its importance, through highlighted texts. That will gain the focus on this text, and there are many ways to focus on a certain text, like using Italic or Bold font, framed text, or with a background, like write a white text on black background or versa. If we used highlighted texts in many places, so nothing will be important. In addition, the utilization of many fonts and colors will be uncomfortable for the user (NAEYC, 2009). Give more space for the main component for instance, if the main subject is a certain figure, so you have to focus on it, by giving it more space in the middle of the screen. For the secondary texts, like options and orders lists, it can be inserted in the side of the screen, because it will not be used, unless it is needed, and you have to get rid from any diagrams of figure that can take the attraction other than the main component.

In relation to this, develop the display structures as it means enabling the learner to read the displayed text in short time, clearly and without effort. Therefore, the following need to be considered such as Divide the scientific subject and display it in a sequence. Keep the same context of each subject, and prevent any overlap and use the multi-page display method. Further, link the displayed components, as the main advantage of the successful computer software is its ability to link the different components of the displayed tests, through the link texts through figures. In general, from the main display styles, is the usage of indicators and figures, which integrated with the displayed texts, to simplify the information to the learner, and enable him to realize the interrelations, because texts only are not enough. Use texts and short comments to explain the figure or the shape, by writing the name of figures that used in educational software.

\section{4- The Learner's Interaction with Software}

Design an interactive program for the learner is not an easy or always possible process, as it is very different than creating a book or any other method, so the following has to be taken into consideration such as ask and do not answer. It means empower the learner to maximize his benefits from the program's possibilities, through searching for the information by himself and validate it. Without any doubt, this will have a great educational value, which represented in the feedback of the learner, when he reached the correct answer. 


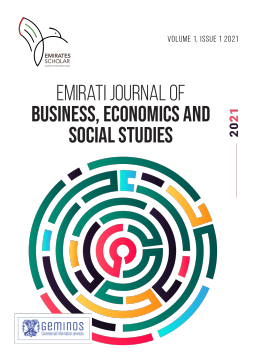

Emirati Journal of Business, Economics, and Social Studies

Vol 1 Issue 1 P: 4 - 302022

DOI: 10.54878

Emirates Scholar

\section{Available at www.emiratesscholar.com}

Further, this can be possible through direct interaction as it means, to enable the learner to address the subject's components directly through the mouse or touch screen, according to the subject nature, and to avoid using keyboard in writing phrases like "right" or "wrong", or to write a number. Therefore, the designer has to avoid the data entry through writing, and depend on mouse, as it is easier and more accurate. In addition, it can help more learners, who are not able to use keyboards. The designer has to avoid using waiting period for presenting something, as it is wrong tradition used in many programs, whereas the program presents a certain text for some seconds, and then delete the screen to present something new. Therefore, the designer has to limit the utilization of specific time of reading the display text, to enable the learner to read the full text. Therefore, the dynamic software is the best, which enables the user to control the display time. Software is not completed, unless it is provided by a part that explain how to deal with this software, so these instructions have to be clear, consistent with the latest version, suitable for the user's experience, and depends on explanatory figure and graphs.

\section{5- Analyse The Learner's Responses}

The learner's inputs must be constantly evaluated, to know whether these inputs are right or wrong, so we can define the reasons of any error. Such as a suitable grammar and spelling, check has to be used, to check the inputs of the learner, as checking the spelling, numbers, words, spacing and the software has to include a huge approved vocabulary. Analyse errors resulted from misunderstanding as it differs from user's input errors, which are just spelling or formatting error, but in this errors, the computer can check whether the learner is on the right way, or he goes far from the right answer. Whereas some programs require the right answer for the learner to proceed, so if he cannot answer, he may get depressed. Therefore, we have to search for a better way than repeating the same questions until getting the right answer, as giving some hints. The learner's feeling of not being able to control the program and its procedure may be depressed. Therefore, the software designer has to be aware about the learner's level and experience, so he can provide the learner with the instructions and maps that enable the learner to study using this software. Control problem can be avoided through the following aspects that provide the learner with some control 


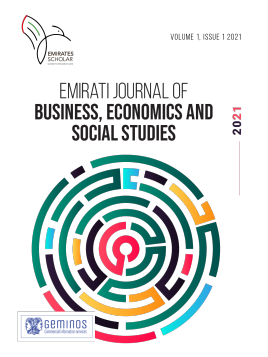
Emirati Journal of Business, Economics, and Social Studies
Vol 1 Issue 1 P: 4 - 302022
DOI: 10.54878
Emirates Scholar

Available at www.emiratesscholar.com

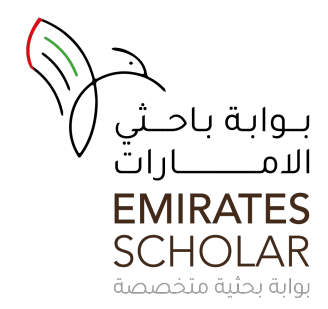

options, as skip certain paragraph, or restore another. This will be done by providing a content list for the program, which includes it components; tools, purpose of each subject and each tool, and provide the tools of restoring any part easily. Avoid using inactive keys or lists, as it will confuse the learner. Provide exit buttons from any place in the software, to save time and avoid confusion. In addition, define the learner's location in the program, through sitemap, to indicate the finished content and the remaining.

\section{Standard Models of Educational Designs}

The diversity of models picture became endless, which identifies educational program design according to its levels in terms of inclusiveness and depth, or nature of used objectives and aimed learning out comes or for perfecting its educational levels. Some of these models will be reviewed in the following.

\subsection{Kemp Model}

The steps of educational program design are coming from identifying the educational purposes, the setting a list of all main topics that will be discussed throughout the program, as well as to define the general objectives. Which will address each topic within the educational program in terms of their tendencies, interests, needs, abilities and other all fields that distinguish them as individuals and groups. Defining behavioural goals that educators hope to achieve in the form of educational behaviours outcomes, which can be measured and observed within it or through its results. Defining the educational program contain which educators will receive. Further, defining the pre-measurement tools in order to identify the pre-experience of educators and their educational awareness level and their emotional and professional as well during this program. In addition to this, choosing the educational activities and its sources, more over specifying the technological education that will be taken throughout the content of program, the matter that will help educators to achieve their behavioural goals.

Since, defining the educational potentials and compromising as it will help in implementing 


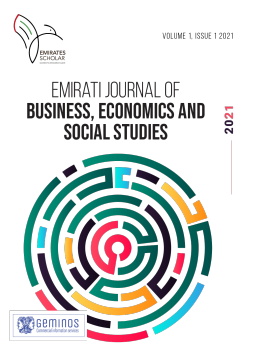
Emirati Journal of Business, Economics, and Social Studies
Vol 1 Issue 1 P: 4 - 302022
DOI: 10.54878
Emirates Scholar

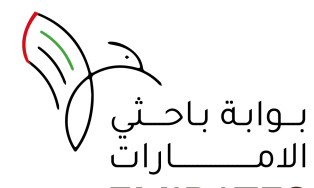

EMIRATES

SCHOLAR

Available at www.emiratesscholar.com

program steps and strengthen the educators learning levels and defining their ability in achieving behavioural goals, as well as making use of the results of this strengthen in reviewing and assessment more than one-step. The following diagram explains the designing steps of educational program and the relation between the steps and each other, with the observation of the steps flexibility and the remarkable mutual effect between different steps.

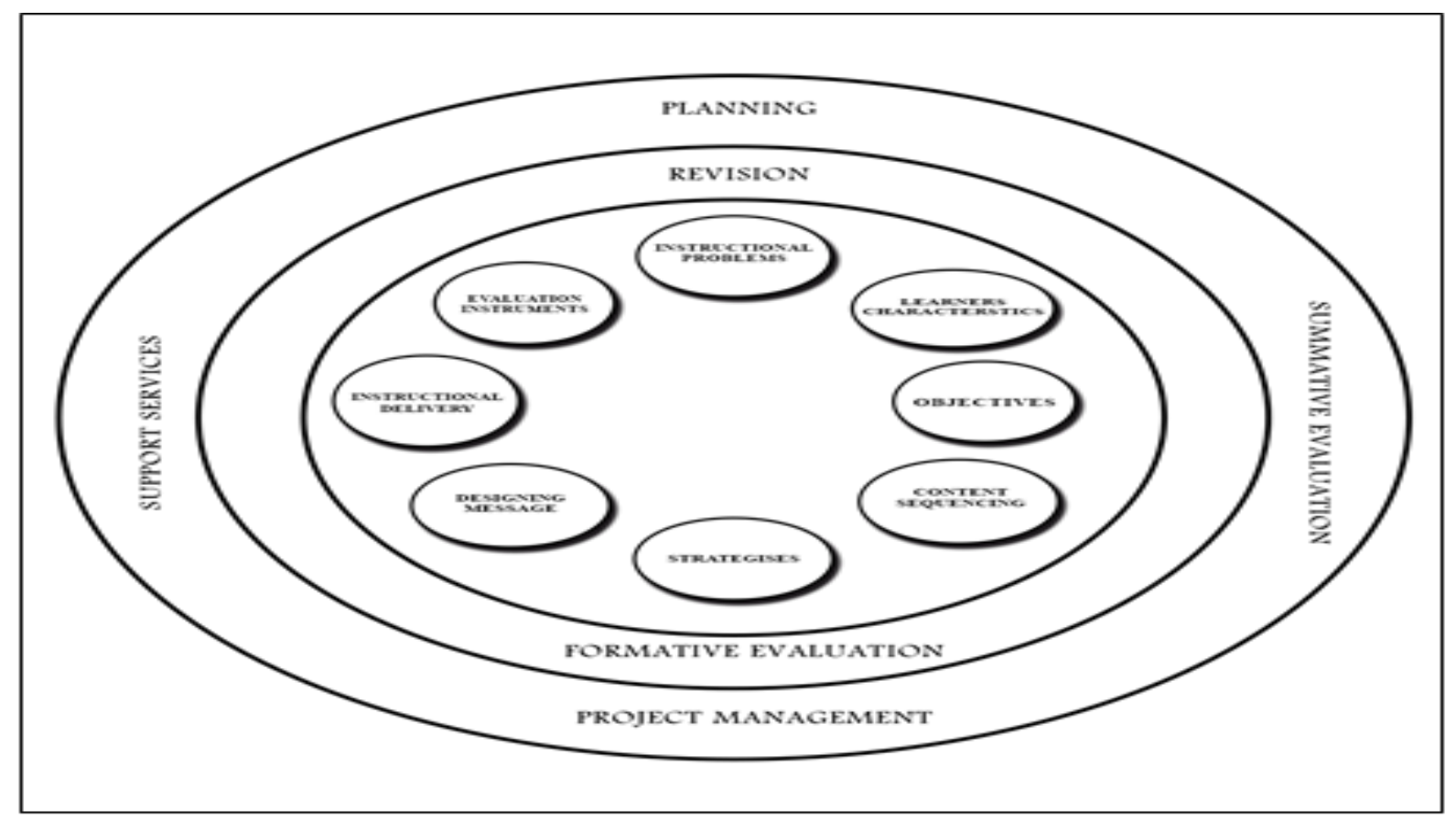

Fig.3 Kemp model of educational program designing (Morrison, Ross, Kemp \& Kalman, 2010).

\subsection{Cyrs and Lowenthal Model}

Cyrs and Lowenthal see that the steps of educational program designing can be achieved through the accurate performance method the re-designing the completely educational process. In order to guarantee these objectives for the educator, as well as to assure the achievements of it to him, as well as to specify the role of both professor and educator as equal and the expected behaviour presented in a form of behavioural changes in prospective, skilful and emotional aspect, it also reflects the help of the teacher. The choice of the educational 


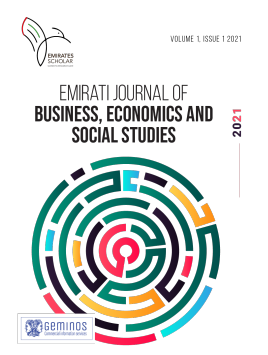
Emirati Journal of Business, Economics, and Social Studies
Vol 1 Issue 1 P: 4 - 302022
DOI: 10.54878
Emirates Scholar

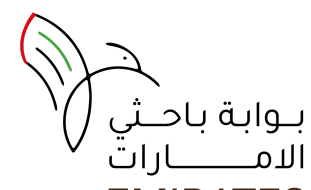

EMIRATES

SCHOLAR

Available at www.emiratesscholar.com

strategies and media are done within the Lowenthal steps that are essential in designing the educational program, includes the following aspects like collecting the input data for educators, forming the performance goals in a behavioural image, designing the pre-tests in order to identify the input behaviour of educators. Further, it facilitates the choosing and containing of the curriculum. Choosing the materials and the available sources of technological education. Producing the rare materials and means (Morrison, Ross, Kemp \& Kalman, 2010).Choosing the appropriate educational inputs implementing the program analysing tests results on long terms final calibration of the program. The next shape will clarify Cyrs and Lowenthal model of educational program design.

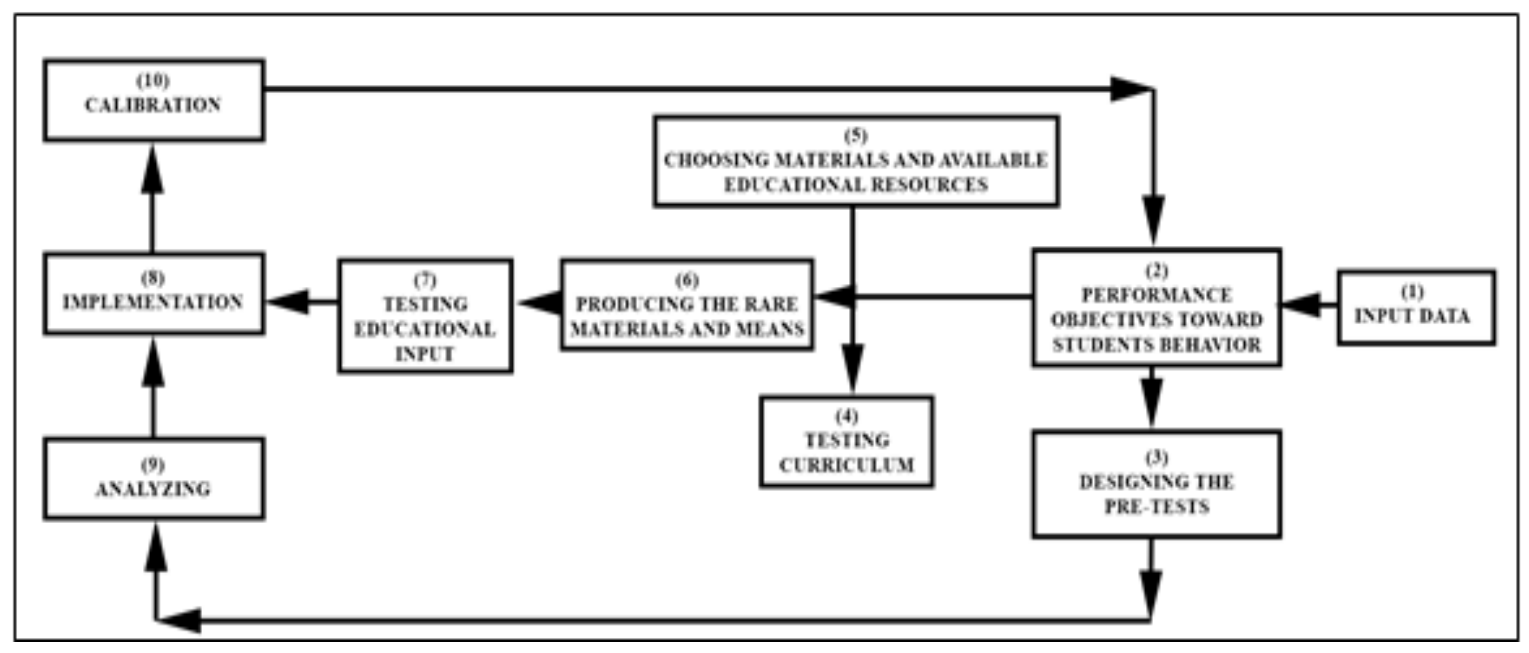

Fig. 4 Cyrs and Lowenthal Model.

\subsection{Hamer Model}

Hammer educational program model consist of three phases: defining with designing phase, analysing phase and developing system phase. The previous phases are divided into steps known as maxi model. Maxi model shortened into six steps known as Mini model, this mini model can be applied by the individual potentials of program developer. Moreover, this mini program can be showed in the following steps as indicated by specifying the problem, specifying behavioural objectives in accordance to the settlement of behaviour performance 


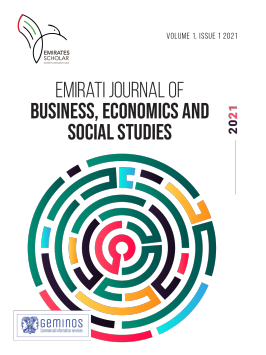

Emirati Journal of Business, Economics, and Social Studies

Vol 1 Issue 1 P: 4 - 302022

DOI: 10.54878

Emirates Scholar

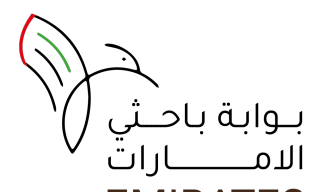

EMIRATES SCHOLAR

Available at www.emiratesscholar.com

criteria, setting educational and media strategies, facts and incidents through developing the proposed model. Further testing the model, editing the procedures and re-doing steps or the course and enriching reference observe the linking of all steps, and the next shape clarifies Hamer mini model of educational system development.

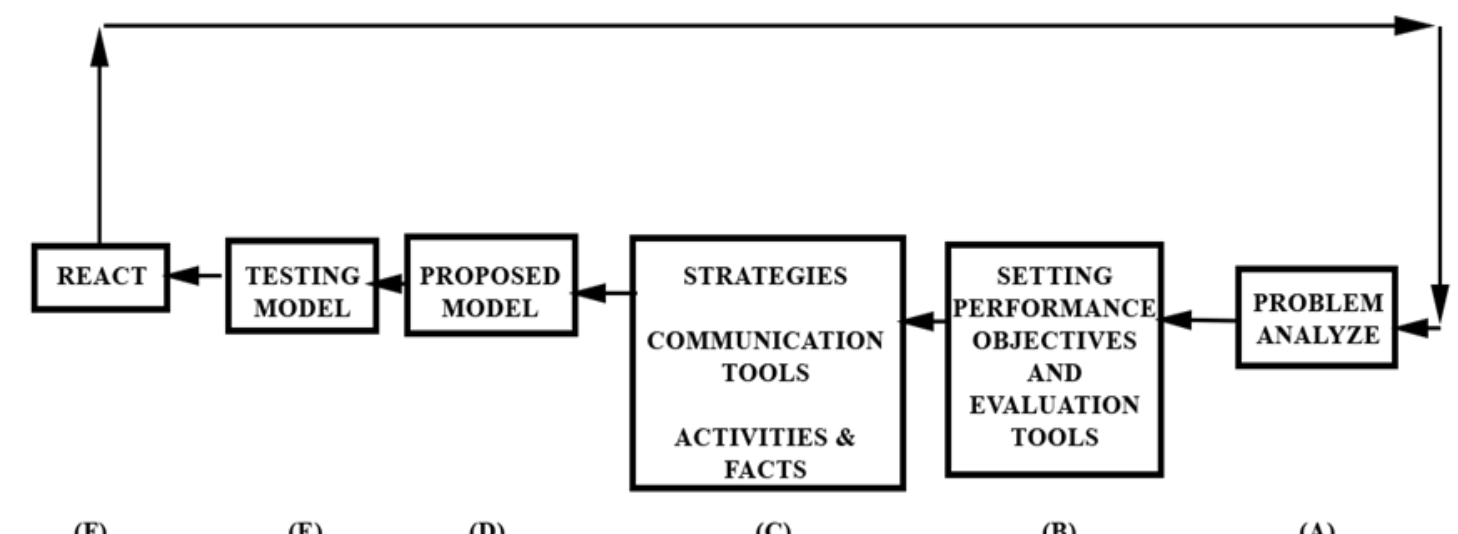

(F)

(E)

(D)

(C)

(B)

(A)

Fig. 5 Hamer Mini Model.

\subsection{Gerlach Model}

Gerlach set a model for educational program planning, focused on that teacher is the organizer, guider, and the only one who able to correct and direct the whole educational process, he isn't only the transporter of educational aspects, this point of view is delivered through an educational program which consist of the next steps as shown in following shape. 


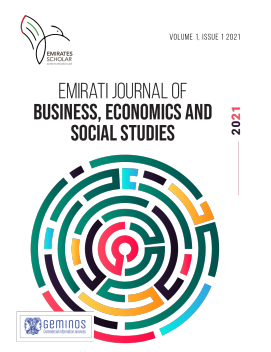

Emirati Journal of Business, Economics, and Social Studies

Vol 1 Issue 1 P: 4 - 302022

DOI: 10.54878

Emirates Scholar

Available at www.emiratesscholar.com

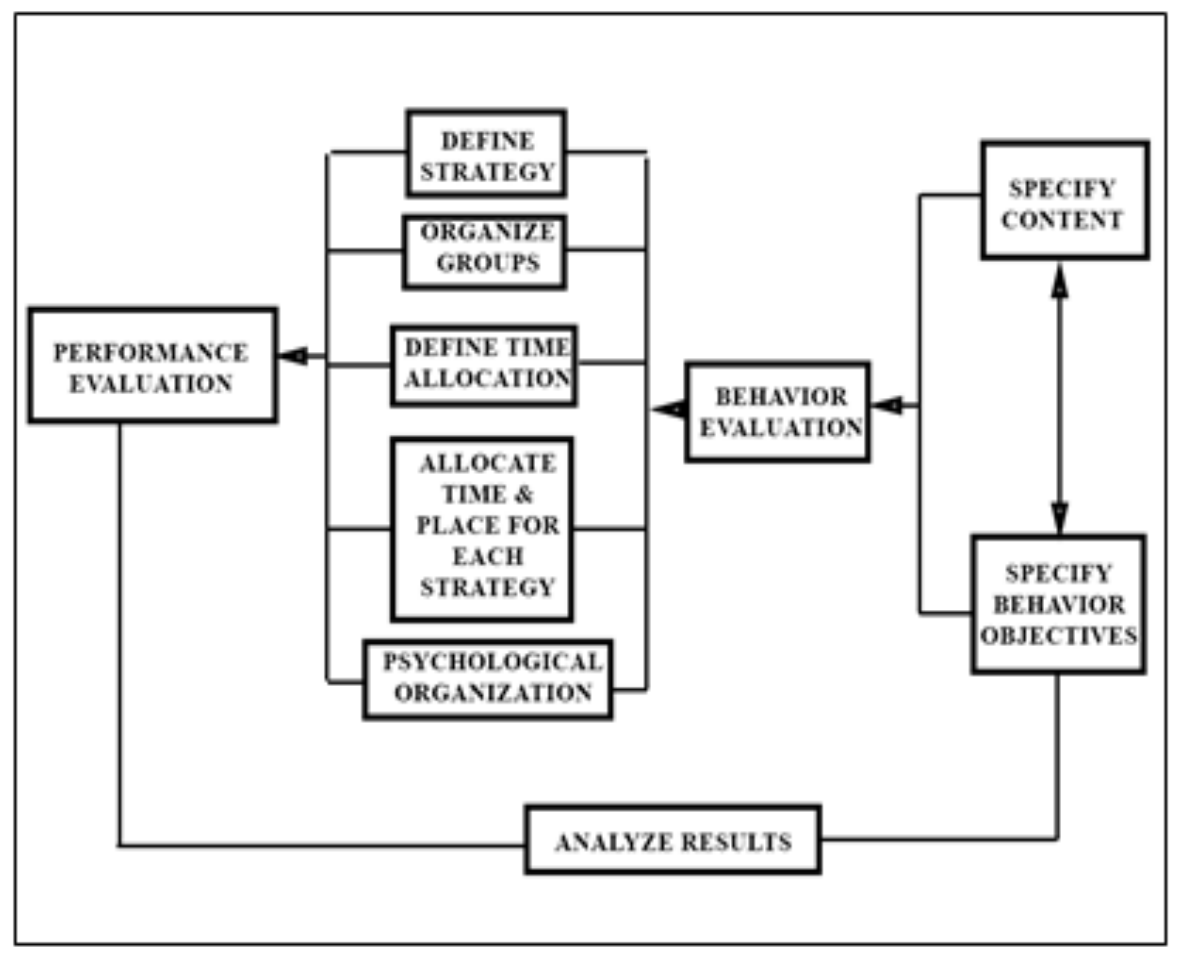

Fig. 6 Gerlach model of educational program designing.

\subsection{Yelon and Berge Model}

Yelon and Berge put a model of educational program designing which shown in the following steps. The actual performance which depends on identifying general educational goals and purposes, as well as identifying characteristics of learners and their tendency for the content of educational program. Defining the final goals, which they aim to achieve in a behavioural image, or educational outputs that can be measured throughout the behavioural performance of the learner. Further, organizing the sequence of content by the form that can achieve aiming goals, moreover in accordance to the characteristics of learners and types of their learning. Next by defining the entrances and strategies of education that cope with the appropriate presentation of the content of educational program, in a form that helps to achieve the hoping goals through introduction, explaining, teaching, viewing, practicing, and enhancing the enrichment of references. Finally, by defining correction means which measures the range of educational program designing, moreover the effectiveness of 


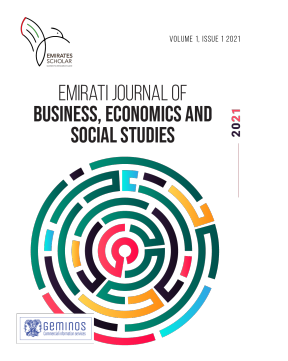
Emirati Journal of Business, Economics, and Social Studies
Vol 1 Issue 1 P: 4 - 302022
DOI: 10.54878
Emirates Scholar

Available at www.emiratesscholar.com

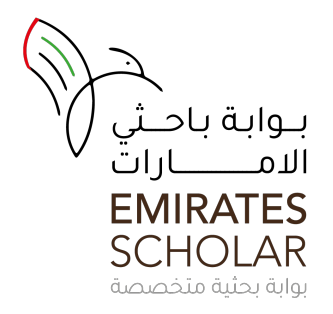

educational program. The following shape declares steps of educational program designing as comprehended by Yelon \& Berge.

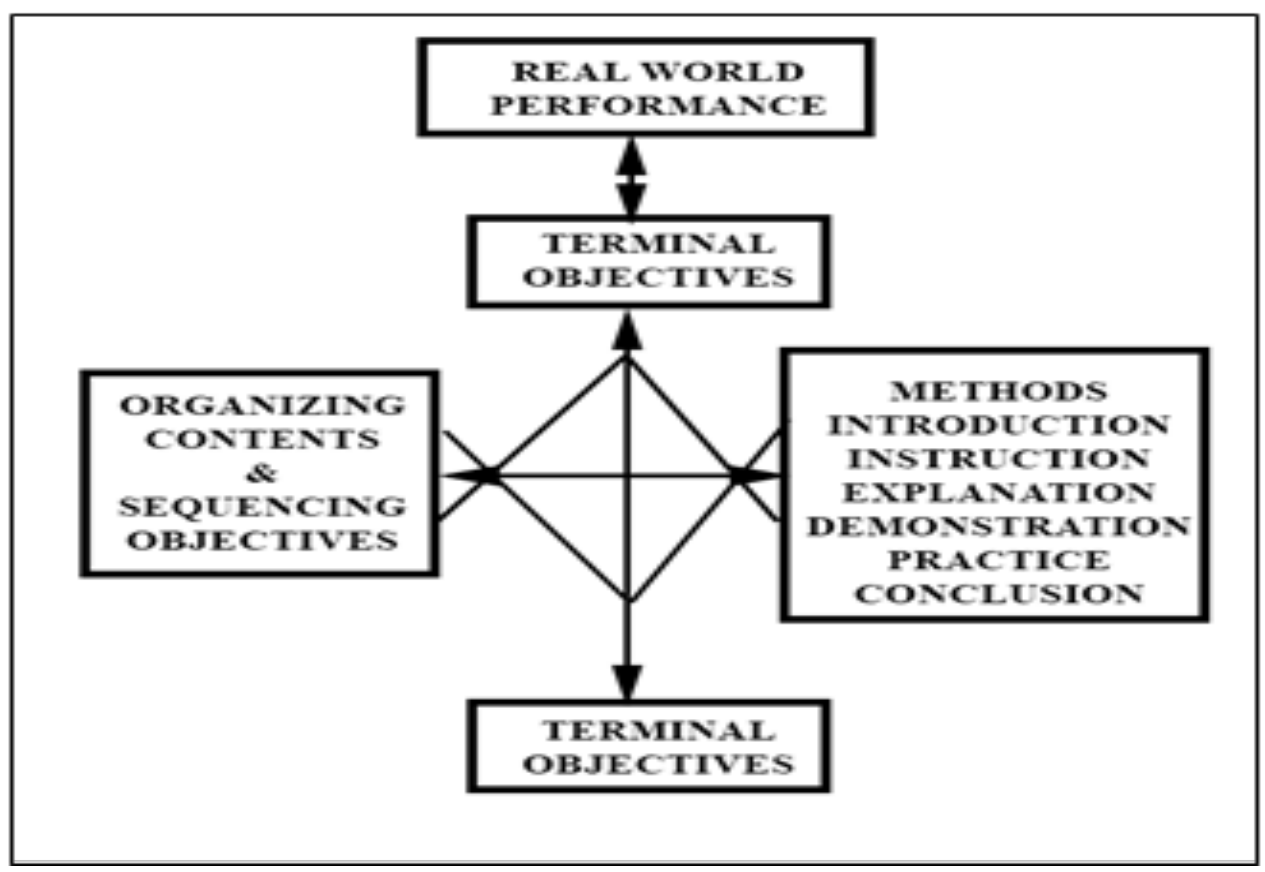

Fig. 7 Yelon \& Berge model of educational program designing (Berge, 1998).

\subsection{Briggs Model}

Briggs sees that educational program designing depending on certain steps that initiates by defining needs and goals that aimed to be achieved. Organizing the curriculum to specify its perfect sequence, which cope with learners' needs, abilities, interests, and tendencies of them in learning. Further, pointing the educational goals for each topic in educational program, which learners aim to achieve through their use to the program. Simply, preparing the assessments for learner performance that can measure the range of educational goals achievements, though to measure the effectiveness and efficiency of the program. Moreover, analysing educational goals in order to reach an accurate identification of educational performances that represent the outputs and results of education. Designing educational strategy, which can represent the scientific content for learners, with the consideration of content organization, and the aiming goals. Further dividing the educational 


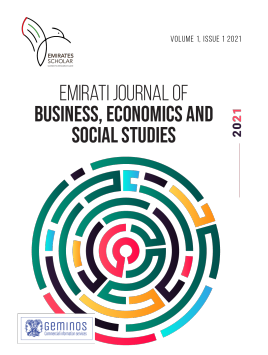
Emirati Journal of Business, Economics, and Social Studies
Vol 1 Issue 1 P: 4 - 302022
DOI: 10.54878
Emirates Scholar

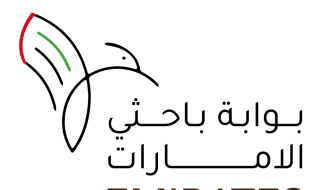

EMIRATES

SCHOLAR

Available at www.emiratesscholar.com

content to sub parts or mini lessons and reforming it in an educational image. Conducting form strengthen/in a sequence for all program steps, in order to highlight weak points of learners and the difficulty in comprehending the content through specifying the assigned final content. The collective/final calibration in order to know the range of educational model effectiveness or even editing any step in the program. The following shape declare steps of Briggs educational program designing.

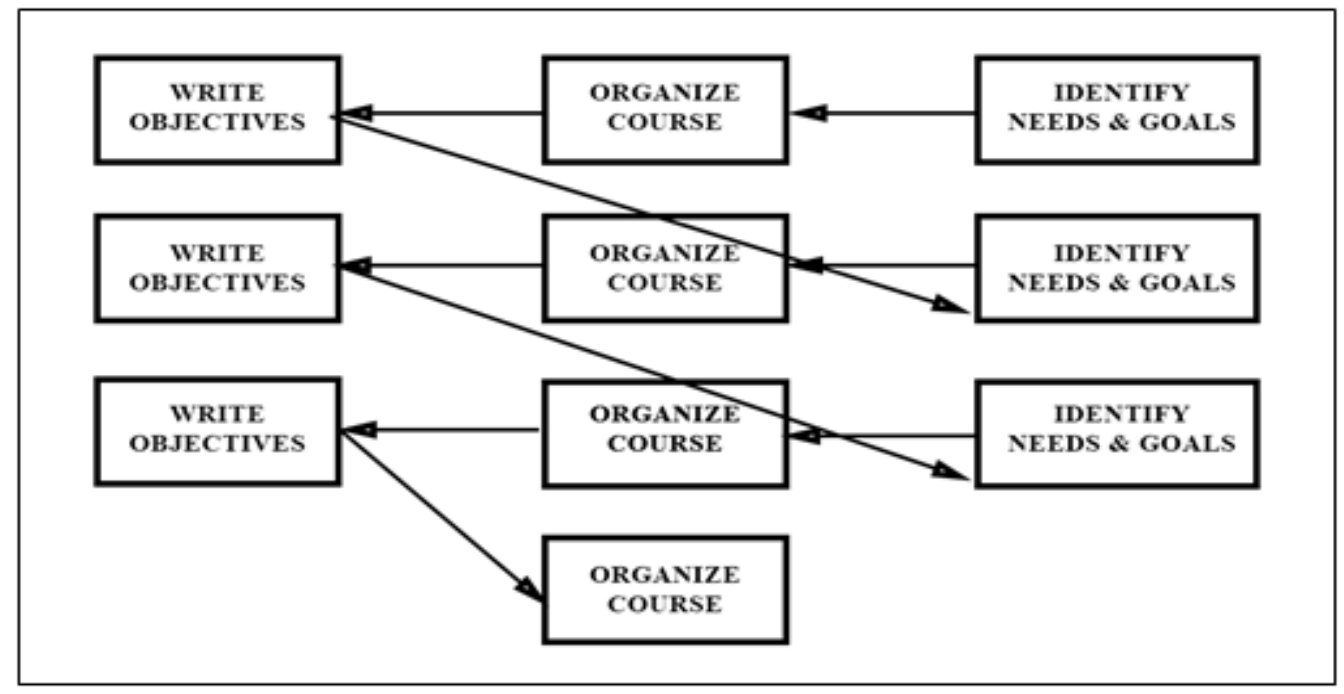

Fig. 8 Briggs model of educational program designing.

\subsection{Dick and Carey Model}

Dick and Carey model is depending on systems method in educational program designing, which includes the identification of general goals and purposes accurately, with the consideration of various characteristics of learners. In addition, the input behaviour of the pre-required learning, as well as to conduct analysis on educational behaviour in each step of the program. In order to identify the conducted goals that declare the aimed results that learners hope to acquire through learning, perceptive, skilful, and emotional which can perform reference tests to judge the educational level of learner through program steps. As well as to develop used learning strategies in the program, which depends on testing educational subjects, producing and compromising between it in a way that achieve learners goals for program. After that planning the formulating calibration in organized educational 


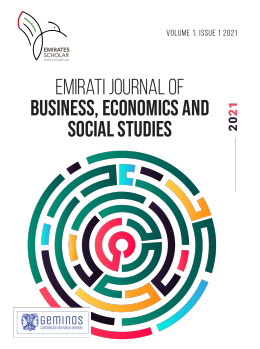

Emirati Journal of Business, Economics, and Social Studies

Vol 1 Issue 1 P: 4 - 302022

DOI: 10.54878

Emirates Scholar

Available at www.emiratesscholar.com

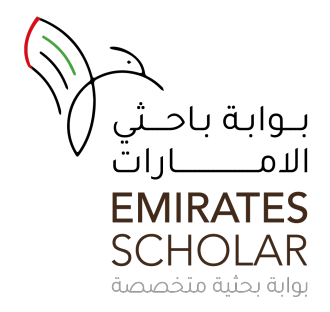

steps that can declare the effectiveness of the program, with the consideration of the characteristics learners and their input behaviours. Educational program designing ends with the planning of final collective calibration in order to calibrate educational outputs. The following shape declare Dick and Carey educational program designing.

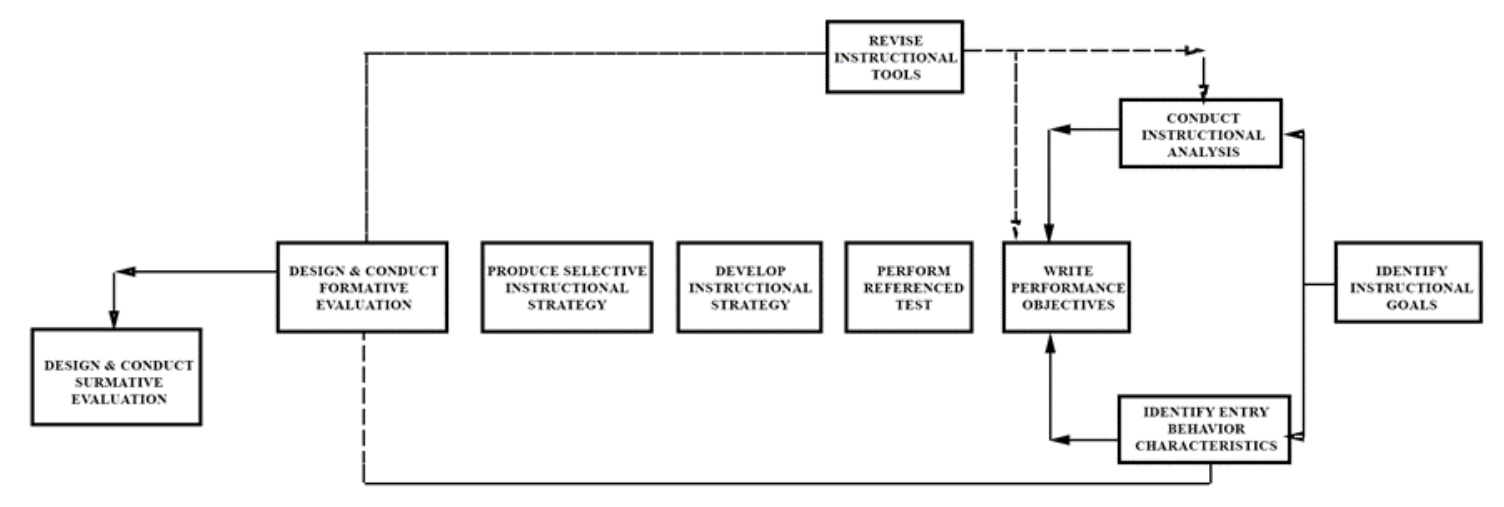

Fig. 9 Dick and Carey educational program designing.

\subsection{Merrill Model}

Merrill and others educational program designing consists of several steps that initiates by knowing basic terms that program deliver through its content. Further by defining educational needs and requirements in order to acknowledge the importance of educational content. Later, Analysing program educational content that learners will receive the identifying clues situations, knowing codes, and terms as well as observing its indications. Later involves the development of presentation forms of educational content by giving some examples that declare divergent thinking, strengthen and enrich hard cases, preparing classification choice, designing educational directions and providing it with the appropriate help and designing sequenced educational strategies which educational program can use. As well as adding alternative strategies for traditional strategies, that leverage the aiming educational efficiency of the program. The models strengthen the e-learning methods and used educational studies in education designing, the following shape declares Merrill educational program designing. 


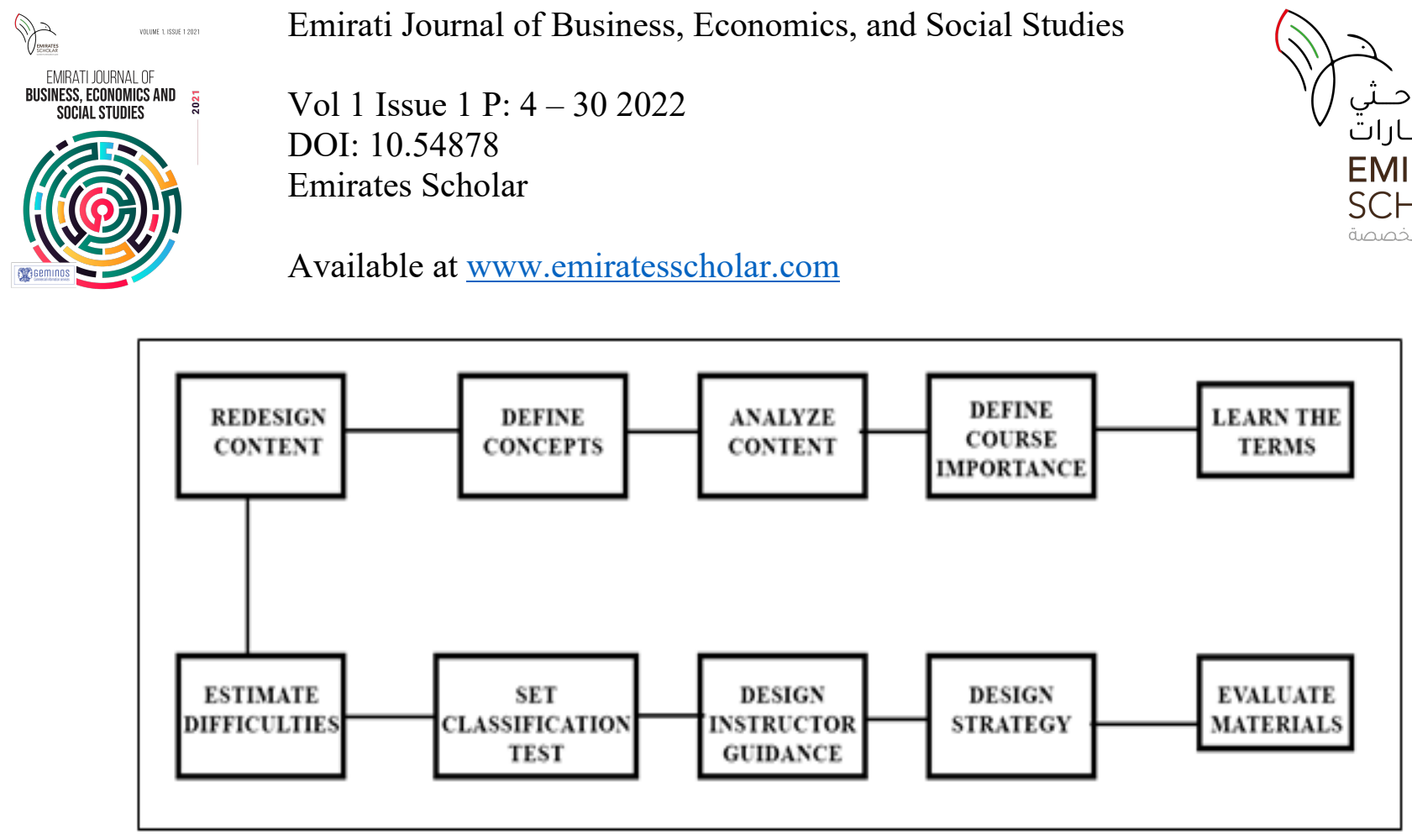

Fig. 10 Merrill educational program designing (Merrill, 1991).

Through the previous preview for some educational designs, we observe that they are flexible designs and it did not specify starting and ending timing for any of program's steps, or even timing for educational technological sources, inputs and educational strategies, more over the moving time from a step to another within the program. It also declares the perfection level that educators will reach, and how to handle situations and problems that may appear and can affect the timing of implementing, sequencing and achieving program goals. It also shows an interactive affect between all program steps, as it may start from any of these steps to the rest of it, though choosing sequence process and following system is only in user's hands. Then, teacher has an important role in the success of this design and compare between what cope with learners needs, the educational content and the actual requirements for learning.

\subsection{Enhanced Self - Learning Theory (Skinner)}

Enhanced Self - learning theory for skinner, who refused to identify teacher through simple mechanic linking between exciting and response, but he sets a new explanation for educator behaviour known as partial requirements, he also claims for the necessity of analysing positive behaviour into conductive steps each one enhances the other and to lead the existence of full response of learner. The idea of analysing and enhancing behaviour in 


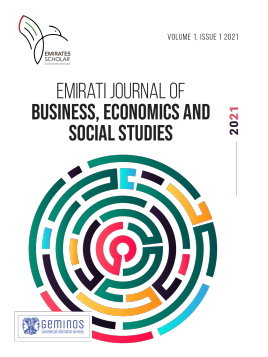

\author{
Emirati Journal of Business, Economics, and Social Studies \\ Vol 1 Issue 1 P: 4 - 302022 \\ DOI: 10.54878 \\ Emirates Scholar
}

\title{
Available at www.emiratesscholar.com
}

focusing on educational strategy, aim to forming learner's behaviour according to the steps like as by defining right and wrong behavioural elements clearly and in a conductive way applicable for measuring and observing. Further by defining the effective enhancements in processing similar educational situations or reforming educational situations.

Employing methods and rules that guarantee for every learner the proper enhancement that push him to show the behavioural performance aimed for forming or editing. Skinner sees that enhancement divided into two types: positive enhancement and negative enhancement, as for positive enhancement it strength and prove learner behaviour, while negative enhancement always represents punishment that ends the unwanted behaviour. as for neglecting or even never enhancing it whether by positive or negative way, it may weaken the response or even vanishing it, then the gradual vanish of this behaviour, enhancement technique can be used in modifying behaviours or even applying it on both teacher and learner. This technique that captured skinner urges him to assist a book named by (usage of enhancement in educational technology), through it, he addresses many of grade education problems aspects. Besides the need of modifying teaching methods, by adding more technological methods, he offers new chances for teachers to use more ways, technologies and strategies in order to enrich enhancement usage in educational process and its improvement.

The educational systems that presented through this theory allows learner to fetch his education according to his own characteristics and self-speed, as to gain an immediate enhancement in every educational step, that depends on Skinners theory. The steps of its implementing and designing it in self-learning includes the specified behavioural aim accurately by defining the on point in education in accordance to learnerexperiences. A start point in education input behaviour and pre-requirements that is dividing educational mission into a series of conductive sequenced steps, with the enhancement of each important step until the goal achieved successfully.

\section{Self - Learning Theory for Educational Systems}




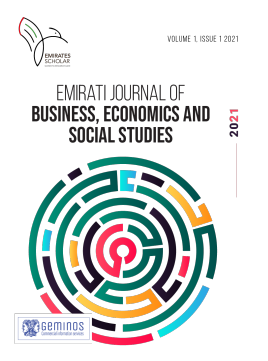

Emirati Journal of Business, Economics, and Social Studies

Vol 1 Issue 1 P: 4 - 302022

DOI: 10.54878

Emirates Scholar

Available at www.emiratesscholar.com

Most of times self-learning be more successful and affective if compared with traditional learning, advantages can be summarized as following. These systems allow each learner to choose what relates to his goals, activities and learning input. Further, Self-learning systems allow each learner to go through his course according to his own individual speed. Selflearning guarantees the interaction of learner with the modified programs through programmer, machine or even educational pile, which is the basic condition in his continual in learning. Self-learning systems allow learner to discover his educational results, and correcting his own path according to that. Through revising educational results of each learner, and discovering educational subjects that learner has perfect speed in learning it, as a prove for his tendency for it, as well as subjects that take too much effort from him proves his weakness in it. As application for these basics, programmed learning includes the provided and organized points that provokes learner and requires a response from him. The response of each learner from it in a certain way. Enhancing learner responses by the individual knowledge for his responses results. Progressing of learner in the program systematically and vanishing learner response mostly in reducing rate of mistake to the probability of completely disappearing it through types of frames.

Frame is always considered the basic direction in constructing program, each frame is specified to achieve or view partial part from the educational content, and frame includes five points: frame number, information, question, answer, and enriching reference and immediate enhancing. Further lead in frames presents topic for learner and provides knowledge for him and addressing problems as well, preparing him to acquire new knowledge. However, discriminating frames help learners to discriminate between several facts that may be unclear. Interlocking frames are for revising or reminding him with previous information at the same time in producing new information. Rote reviewing frames expose problems or similar topics for what have been displayed before. Restarted review frames expose the subject in a different way of the previous different skills. Generalizing frames shows specific characteristics or common features between previous problems and topics. Further, fading frames that re- 


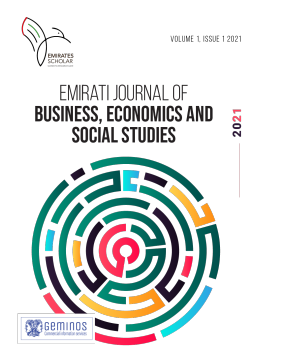
Emirati Journal of Business, Economics, and Social Studies
Vol 1 Issue 1 P: 4 - 302022
DOI: 10.54878
Emirates Scholar

Available at www.emiratesscholar.com

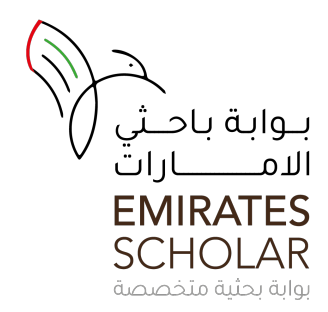

provide knowledge in a way that lack hinting power. Moreover, specifying frame gives student certain example to clarify a following general rule for these frames.

On the other hand, chaining frames is a series of frames set to establish a group of responses, starts by providing knowledge during series and ends with requesting learner to express the whole series. While, concept-formatting frame depends on a series of frames which consisting certain awareness followed by generalization. Practice frames are used in comprehending educational knowledge and presented through relations between things. Testing frames are aiming to test the learner in the educational points that already discussed, it comes after studying each point provided by hinting system. While, forcing frames are viewing certain knowledge, and asking learner to give right response, without the necessity to understand this knowledge. This further includes educational goals, defining the input level for learners, defining scientific material, which approving the required goals, defining viewing content system, writing program frames, correcting program-forming and collective. Programmed learner has two main types of programs, differs in manner and the way in providing the educational subject for learners, although they go along with each other.

\section{1- Linear Programs}

It is called the liner or systematic programs, which the educational subject is divided into a sequence of frames, whereas each frame is ended by a question related to its content. However, the purpose of this question not to examine the learner, but to help him through enhancing his rapid answer, through right answers until the end of the program.

\section{2- Branching Programs}

The programs include much information more than any other programs - linear programs - whereas each frame is ended by a multiple-choice question, if the learner answer with the right answer, he will get an immediate enhancing to go for the second frame. Otherwise, if the answer was wrong, the program will refer the learner to a branch information that include information about the right answers.

\section{Conclusion}




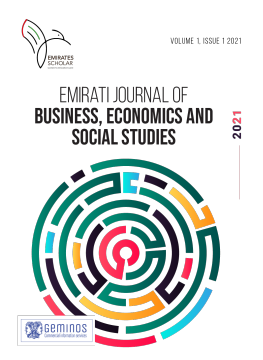

Emirati Journal of Business, Economics, and Social Studies

Vol 1 Issue 1 P: 4 - 302022

DOI: 10.54878

Emirates Scholar

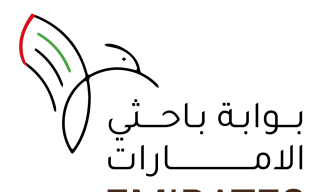

EMIRATES

SCHOLAR

Available at www.emiratesscholar.com

There are many considerations have to be taken into account while designing elearning systems, which are education design, the selection of references and education methods, education references, e-learning standards and measuring the impact of using ITC in education. The current common criteria of E-learning are not yet able to reach the level of get the certification of ISO, as it is still just Specifications, Guidelines, or Criterions, because the e- learning system and its LMS and educational Content are still in the phase of rapid changes. While e-learning still needs to reach the stability criteria. SCORM criteria are the most comprehensive standards for establishing and designing e- learning systems and the educational programs, whereas it seeks to reach the Accessibility like the ability of defining the location and accessing the educational content from any place. Adaptability such as the ability to adopt, to meet the needs of persons and educational institutions. Affordability such as it is the ability to increase the efficiency and productivity, while decreasing the time and cost of education delivery. Durability like the ability to use the content, even if the used technology is changed, as the upgrade of the operating system or LMS. Further defines the interoperability that is the ability of communication among different educational platforms and tools, and to work together in an efficient manner and reusability that is the ability of modifying the content, and re-use it for many times, by using different tools and platforms.

\section{Closure}

The researcher has addressed the subject of standards of building e-learning systems, to find a definition of e-learning standards, through the explanations related to e-learning, standards of building and evaluating the educational program and the followed steps in this field. He is hoping that this research will contribute in enhancing the scientific addressing of this subject to reach the application of comprehensive quality standards in this field.

\section{References}

Aldalalah, O. A., \& Ababneh, Z. W. M. (2015). Standards of Multimedia Graphic Design in Education. Journal of Education and Practice, 6(17), 102-110. 


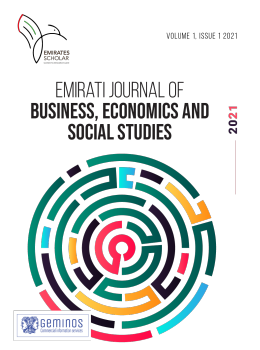

Emirati Journal of Business, Economics, and Social Studies

Vol 1 Issue 1 P: 4 - 302022

DOI: 10.54878

Emirates Scholar

Available at www.emiratesscholar.com

Alonso, F., López, G., Manrique, D., \& Viñes, J. M. (2005). An instructional model for web-based e-learning education with a blended learning process approach. British Journal of educational technology, 36(2), 217-235.

Arkorful, V., \& Abaidoo, N. (2015). The role of e-learning, advantages and disadvantages of its adoption in higher education. International Journal of Instructional Technology and Distance Learning, 12(1), 29-42.

Berge, Z. L. (1998). Guiding principles in Web-based instructional design. Educational Media International, 35(2), 72-76.

Bouras, C., Nani, M., \& Tsiatsos, T. (2003, June). A SCORM-conformant LMS. In Proceedings of Ed-Media (pp. 10-13).

Codone, S. (2001) An E-Learning Primer, Raytheon Interactive. Available from: http://faculty.mercer.edu.

Cohen, H. G. (1992). Two teaching strategies: Their effectiveness with students of varying cognitive abilities. School Science and Mathematics, 92(3), 126-132.

Deperlioglu, O., Sarpkaya, Y., \& Ergun, E. (2011). Development of a relational database for learning management systems. TOJET: The Turkish Online Journal of Educational Technology, 10(4).

E-learning Portal (2009). E-learning glossary. Retrieved from http://www.elearningguru.com/glossary/e.htm.

Fresen, J. W. (2011). Factors influencing lecturer uptake of e-learning. Teaching English with Technology, 11(1), 81-97.

Garrison, D.R., \& Anderson, T. (2003). E-learning in the 21st century. A framework for research and practice. London: RoutledgeFalmer.

Governors State University, Center for Online Learning and Teaching. (2008). E-learning glossary. Retrieved from www.govst.edu/elearning/default.aspx.

Guri-Rosenblit, S. (2005). 'Distance education'and 'e-learning': Not the same thing. Higher Education, 49(4), 467-493. 


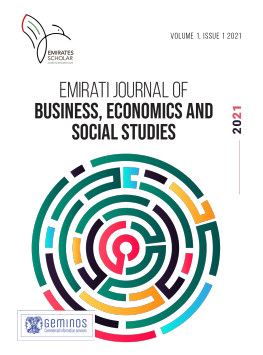

Emirati Journal of Business, Economics, and Social Studies

Vol 1 Issue 1 P: 4 - 302022

DOI: 10.54878

Emirates Scholar

Available at www.emiratesscholar.com

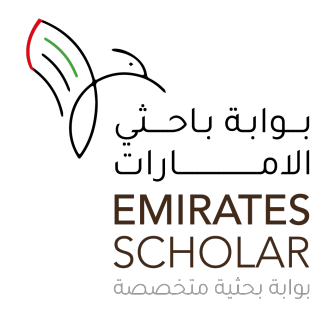

Hassan, N. F. (2015). Implementation of Innovation to Improving Leadership Skill of TVET Student. Journal of Education and Practice, 6(1), 85-87.

Leidner, D. E., \& Jarvenpaa, S. L. (1995). The use of information technology to enhance management school education: A theoretical view. MIS quarterly, 265-291.

Marquès, P. (2006). Definición del e-learning. Retrieved from www.pangea.org/peremarques.

Merrill, M. D. (1991). Constructivism and instructional design. Educational technology, 31(5), 4553.

Morrison, G. R., Ross, S. M., Kemp, J. E., \& Kalman, H. (2010). Designing effective instruction. John Wiley \& Sons.

Naber, L., \& Köhle, M. (2006). E-nhance Lectures. Journal of Digital Information, 3(4).

National Association for the Education of Young Children, 2009. http://www.naeyc.org/files/naeyc/file/positions/PSDAP.pdf

Rahmana, A., Kamil, M., Soemantri, E., \& Olim, A. (2014, September). Simulation-based training model to develop project management competencies. In Management of Innovation and Technology (ICMIT), 2014 IEEE International Conference on (pp. 301-305). IEEE.

Rennie, F., \& Morrison, T. (2013). E-learning and social networking handbook: Resources for higher education. Routledge.

Rennie, F., \& Morrison, T. (2013). E-learning and social networking handbook: Resources for higher education. Routledge.

Sandoval, Z. V. (2016). The Re-Design Process of an Instrument to Evaluate Usability in Online Courses. Issues in Information Systems, 17(3).

Smedley, J. (2010). Modelling the impact of knowledge management using technology. OR insight, 23(4), 233-250.

Wagner, N. L., Hassanein, K., \& Head, M. M. (2008). Who is responsible for e-learning success in higher education? A stakeholders' analysis. Educational Technology \& Society, 11(3), 26-36.

Zamfir, A. (2008, April). Impact of using computer applications in education on teaching-learning 


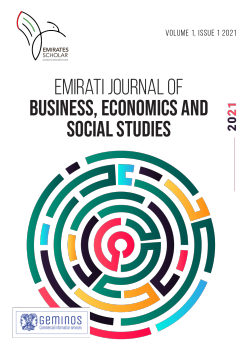

Emirati Journal of Business, Economics, and Social Studies

Vol 1 Issue 1 P: 4 - 302022

DOI: 10.54878

Emirates Scholar

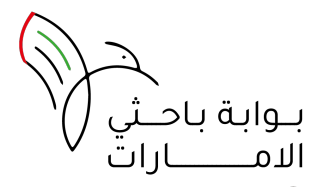

EMIRATES SCHOLAR

Available at www.emiratesscholar.com

process. In Q. Li, S. Y. Chen, \& A. Xu (Eds.), WSEAS International Conference. Proceedings. Mathematics and Computers in Science and Engineering (No. 7). World Scientific, Engineering Academy, and Society. 